\title{
Operative Management of Distal Femur GCT by Sandwitch Technique for Joint Salvage: A Case Report and Review of Literature
}

\author{
Dr. Pradip Kumar Ghosh ${ }^{1}$, Dr. Harendra Kumar ${ }^{2}$, Dr.Debdutta Chatterjee ${ }^{3}$, \\ Dr. Arnab Sarkar ${ }^{4}$, Dr.Chiranjit De ${ }^{5}$, Dr.Soudip Sinha ${ }^{6 .}$ \\ ${ }^{I}$ (Orthopaedics / Bmch / India) Associate Professor, ${ }^{2}$ (Orthopaedics /Bmch /India) Resident Doctor \\ ${ }^{3}$ (Orthopaedics /Bmch /India) professor, ${ }^{4}$ (Orthopaedics/Bmch/India)Resident Doctor \\ ${ }^{5}$ (Orthopaedics/Bmch/India)Resident Doctor, ${ }^{6}$ (Orthopaedics/Bmch/India)RMO
}

\begin{abstract}
GCT is locally aggressive benign bone tumour located eccentrically in epiphysis. Most common site is distal femur in 20-40 yrs age group with slight female predominance. We report a case of 21 yrs female patient presented with pain and swelling over lateral aspect of right distal femur without any history of significant trauma .X-RAY, MRI, and incisional biopsy done. Patient was managed by Sandwitch technique to preserve articular cartilage. Histopathological examination (HPE) of excised mass confirmed the diagnosis. Till last follow-up (1year), patient is symptom free with no evidence of recurrence.
\end{abstract}

Keyword: Distal femur, DFLP, GCT, Joint salvage, Sandwitch technique.

\section{Introduction}

According to Mayo clinic series, GCT represents 5\% of neoplasm of bone, most common age group 20-40 yrs [1].Most common location is distal femur [2]. Although these tumours typically benign, pulmonary metastasis occurs in approximately $3 \%$ of cases[3]. GCT are frequently locally aggressive tumour[4]. We report a case of right distal femur GCT managed by sandwitch technique to preserve articular cartilage of joint in 21 yrs female patient. The purpose is to evaluate result of Sandwitch technique in the management of GCT for joint salvage.

\section{Case report}

21 yrs female patient presented to orthopaedic OPD with complain of pain and swelling over lateral aspect of right distal femur since 6 months.Pain was initially during activity but since last 3 months pain was present even during rest.No history of significant trauma .General examination was unremarkable with no significant proximal lymphadenopathy and distal neurovascular deficeit. Local examination revealed tenderness over lateral aspect of right distal femur with no skin changes and no lacal rise of temperature.Radiological examination of right distal femur with knee joint revealed eccentrically located lytic lesion that abut the subchondral bone (fig.1).MRI shows GCT of right distal femur with preservation of articular cartilage.Incisional biopsy shows GCT (fig.2)

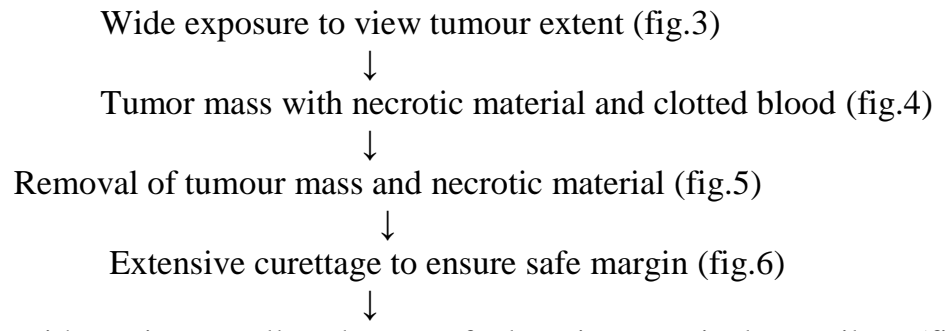

Packing the empty space with corticocancellous bone graft along intact articular cartilage (fig.7)

A layer of gelfoam is laid upon bone graft (fig8)

Application of bone cement (fig.9)

$\downarrow$

Cavity is completely packed with bone cement (fig.10)

$\downarrow$

Fixation with DFLP and screw (fig. 11) 
Operative Management Of Distal Femur Gct By Sandwitch Technique For Joint Salvage:

Tumour mass with necrotic material was sent for Histopathological examination that confirmed diagnosis of GCT (fig.12)

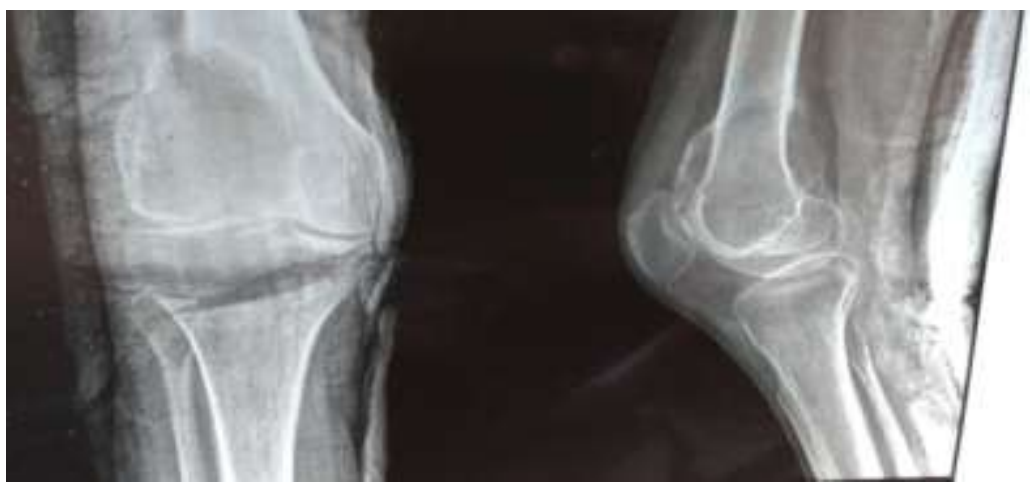

Fig.1

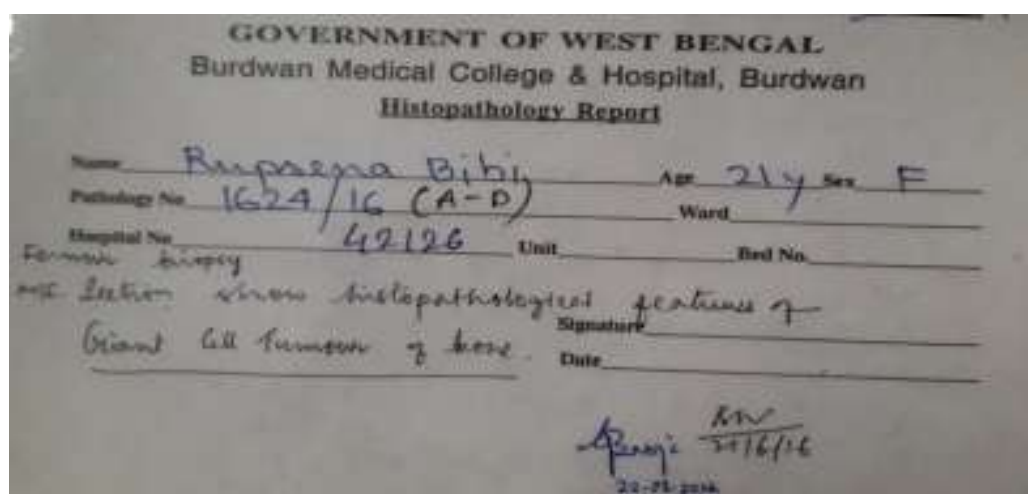

Fig.2

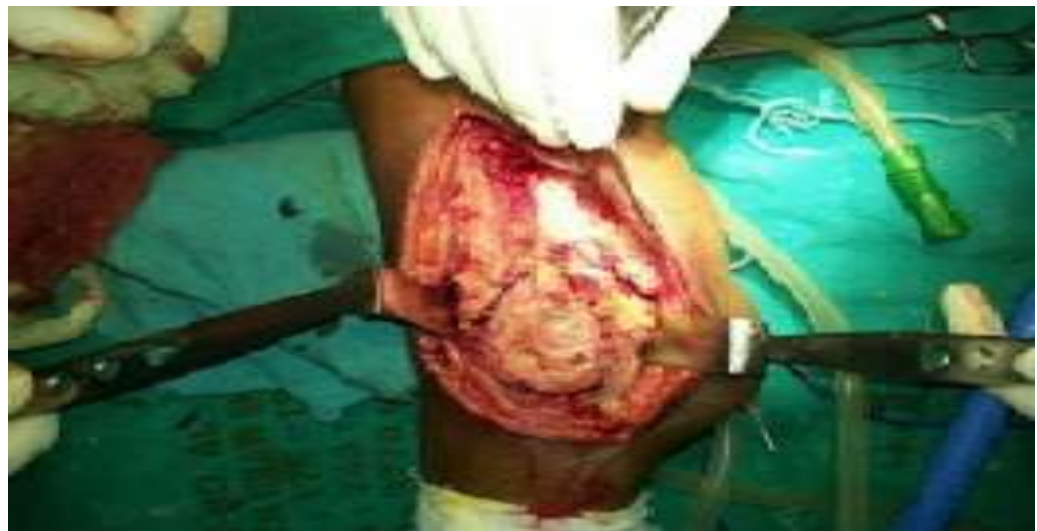

Fig.3

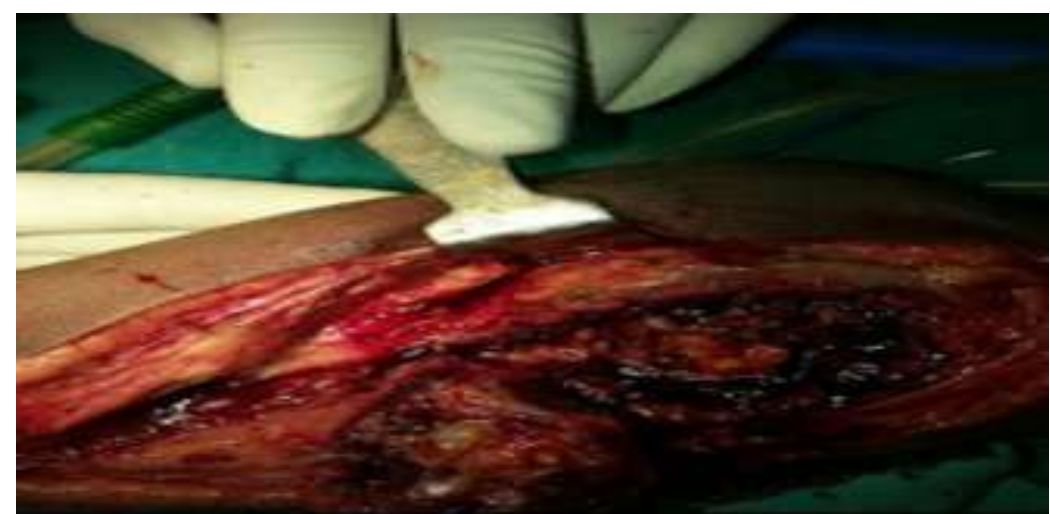

Fig.4 


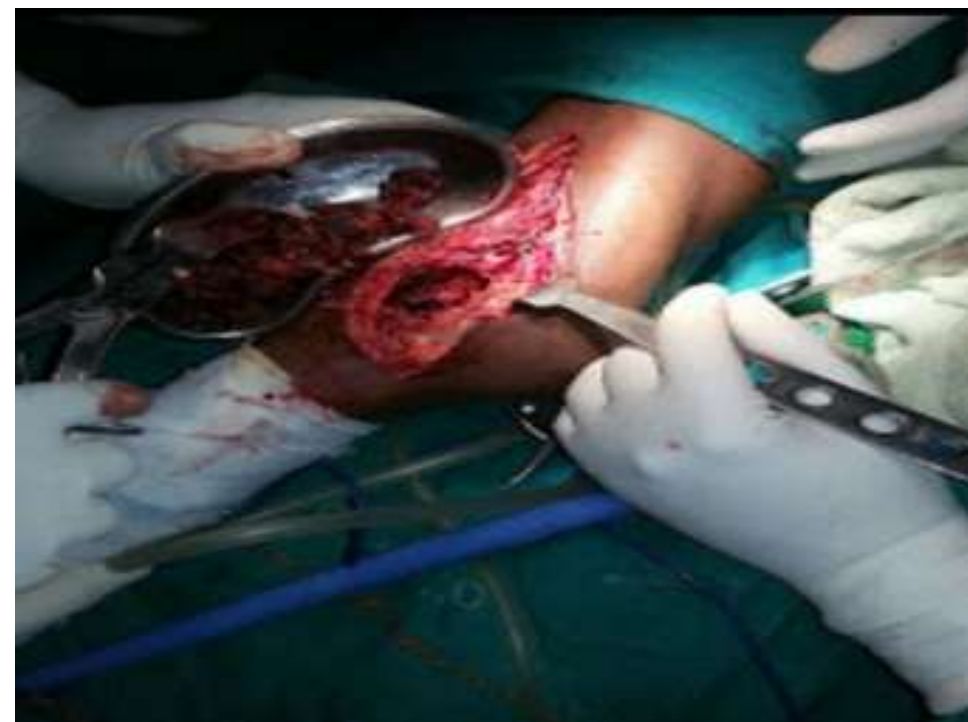

Fig.5

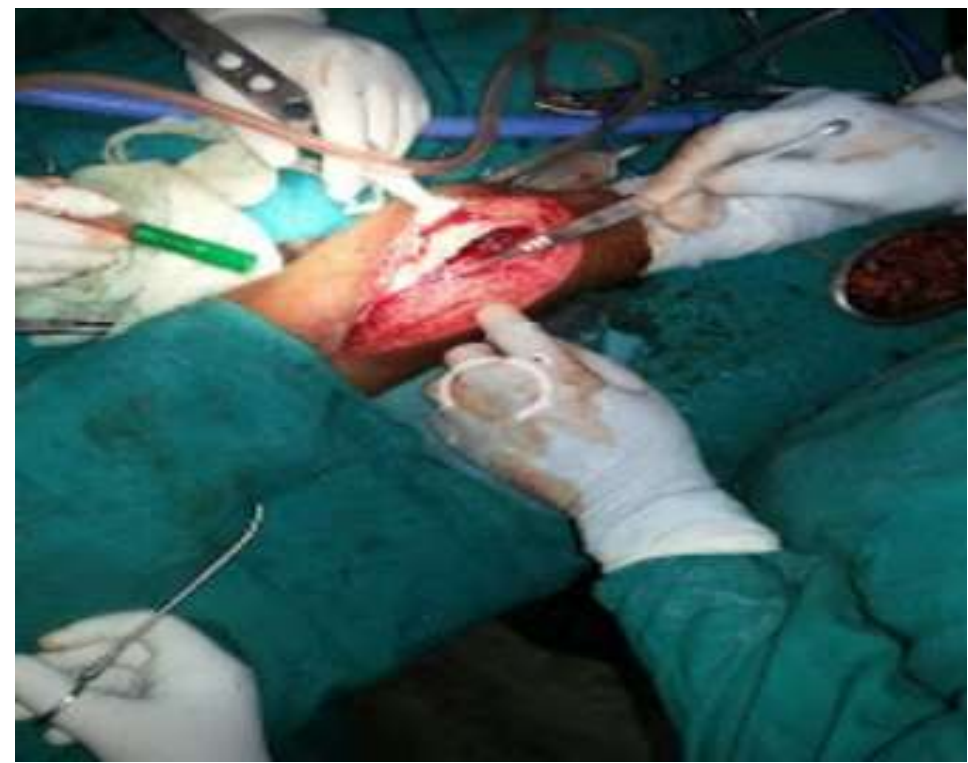

Fig.6

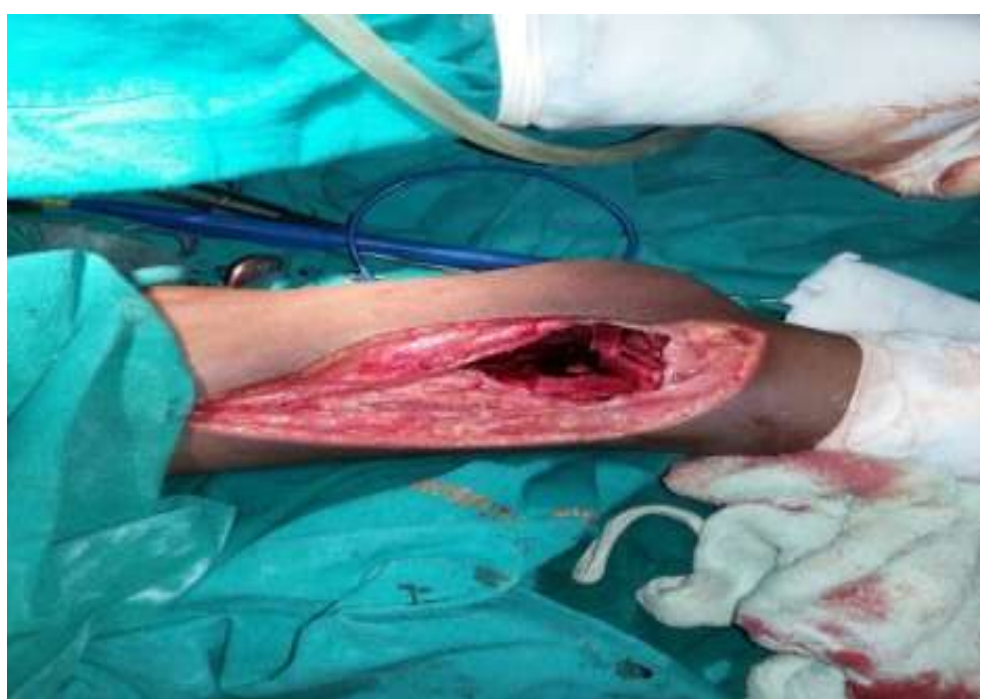

Fig.7 


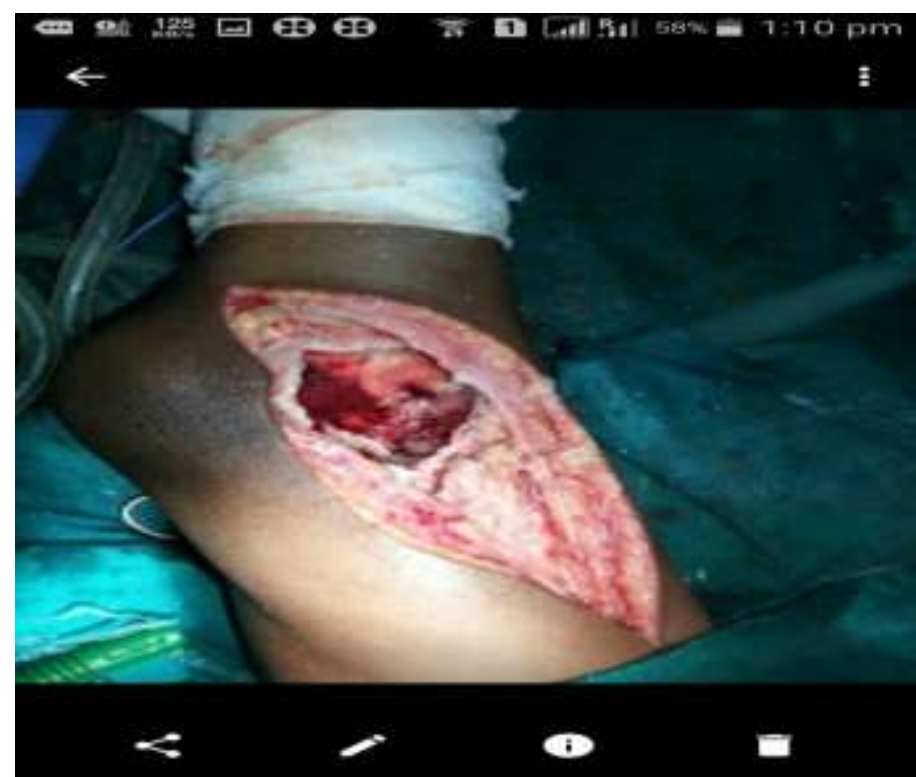

Fig.8

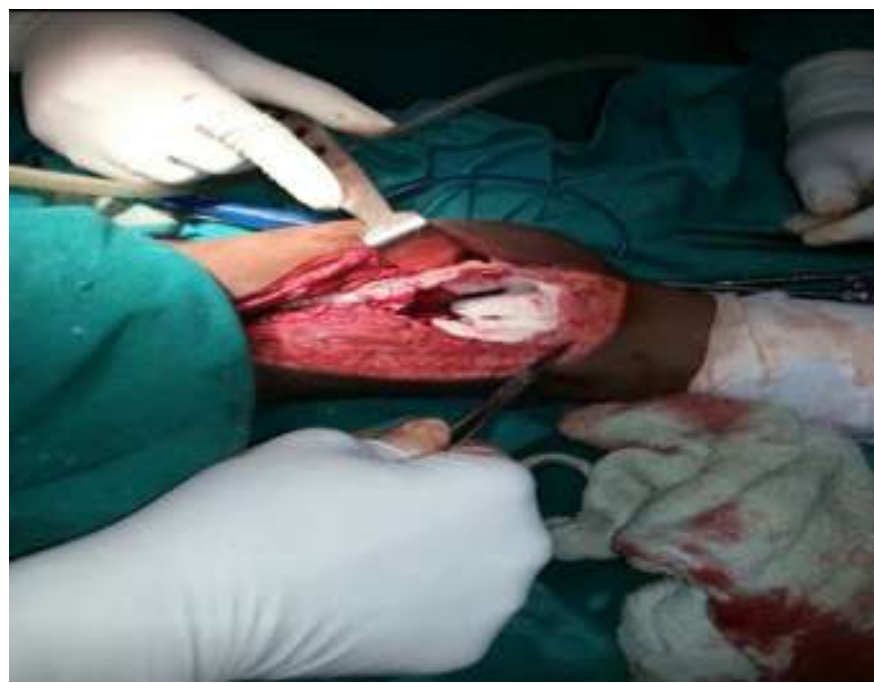

Fig.9

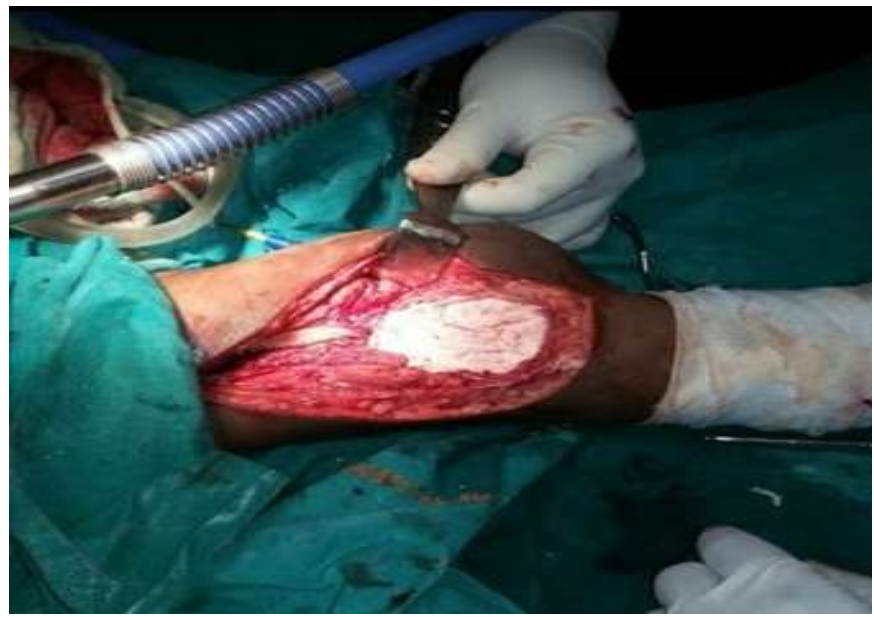

Fig.10 


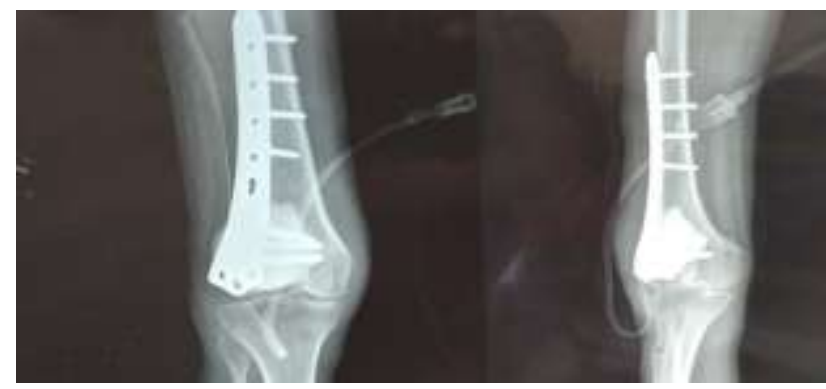

Fig.11

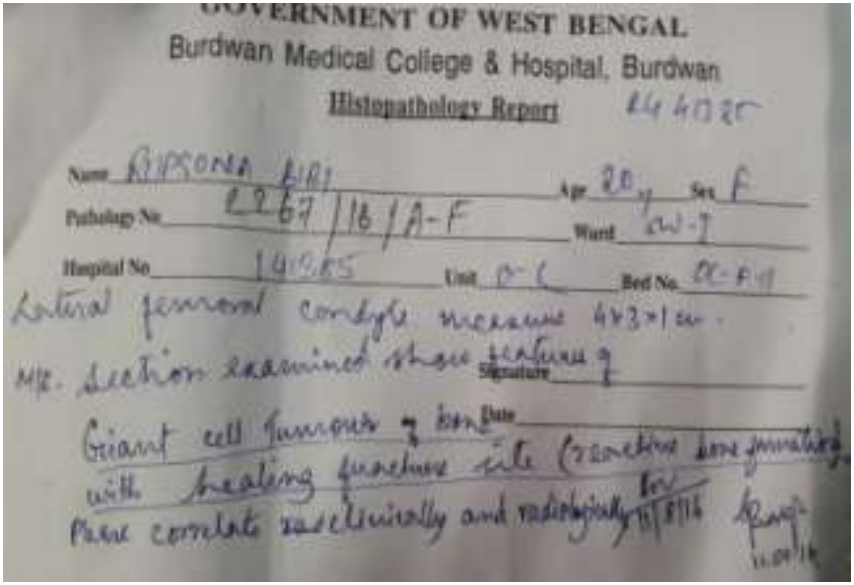

Fig.12

\section{Discussion}

The most common site of GCT is distal femur in 20-40 yrs age group with slight female predominance eccentrically located in epiphysis and usually abut the subchondral bone.Extensive curettage with preservation of articular cartilage should be done wherever possible [5].The alternative option for filling the void space after curettage is either with bone graft or with bone cement [6].Sandwitch technique uses the advantage of bonegraft and bone cement taking care of articular cartilage [7].At final follow-up (after $1 \mathrm{yr}$ ), the functional evaluation is done using MUSCULOSKELETAL TUMOUR SOCIETY SCORE [8]

\section{Conclusion}

The sandwitch technique reconstructing the subchondral bone after extensive curettage produce good functional result with low reccurrence rate.Insertion of cortico cancellous bridge between subchondral bone and bone cement may retard the process of early cartilage degeneration. The limitation of our study is short duration follow up (1yr only) and only one patient.Using sandwitch technique joint salvage for GCT around joint without involving articular cartilage, may be a good option.

\section{Acknowledgement}

Author sincerely thanks to patient and patient relatives.

\section{Reference}

[1]. Campbells Operative Orthopaedics, 12th edition, Tumours.Benign/Aggressive tumors of bone, vol.1,S.Terry Canale, James H.Beaty, page no.887

[2]. Campbells Operative Orthopaedics , 12 th edition , Tumours.Benign/Aggressive tumors of bone, vol.1,S.Terry Canale ,James H.Beaty,page no. 887

[3]. Campbells Operative Orthopaedics , 12 th edition , Tumours.Benign/Aggressive tumors of bone, vol.1,S.Terry Canale ,James H.Beaty,page no.887

[4]. Campbells Operative Orthopaedics , 12 th edition , Tumours.Benign/Aggressive tumors of bone, vol.1,S.Terry Canale ,James H.Beaty,page no.887

[5]. J Knee surgery,2015apr ;28(2):157-64.doi:10.1055/s-0034-1373738.epub2014apr21

[6]. J Knee surgery,2015apr ;28(2):157-64.doi:10.1055/s-0034-1373738.epub2014apr21

[7]. J Knee surgery,2015apr ;28(2):157-64.doi:10.1055/s-0034-1373738.epub2014apr21

[8]. J Knee surgery,2015apr ;28(2):157-64.doi:10.1055/s-0034-1373738.epub2014apr21 